\title{
Sustainable Production of Helical Pinion Gears: Environmental Effects and Product Quality
}

\author{
Jeong-Hwan Yun ${ }^{1,2}$, Myeong-Sik Jeong,*, Sang-Kon Lee', Jin-Woo Jeon', Jin-Young Park', and Gyu Man Kim,,*** \\ 1 Ultimate Manufacturing Technology Center, Korea Institute of Industrial Technology, Techno sunhwan-ro, Yuga-myeon, Dalseong-gun, Daegu 711-880, South Korea \\ 2 School of Mechanical Engineering, Kyungpook National University, \#1370, Sangyuk-Don, Bukgu, Daegu 702-701, South Korea \\ \# Corresponding Author / E-mail: gyuman.kim@knu.ac.kr, TEL: +82-53-950-7570, FAX: +82-53-950-6550 \\ *These authors equally contributed as corresponding authors
}

KEYWORDS : Energy-saving process, Sustainable production, Helical pinion gear, Cold extrusion, Environmentally friendly process

\begin{abstract}
The manufacture of helical pinion gears has involved machining processes such as hobbing and shaving to achieve the required dimensional accuracy. However, these conventional processes have some disadvantages such as excessive material loss, low productivity, high-energy consumption, and high carbon emissions. To overcome these problems, a cold extrusion process is applied to the manufacture of helical gears. In this study, we analyze the environmental effects of the cold extrusion process, designed for the sustainable production of helical gears. We quantitatively analyze the environmental effects of the conventional machining and cold extrusion processes, using the Life Cycle Assessment technique in accordance with ISO 14000. This analysis includes the energy consumption and carbon emissions for a helical gear manufactured using the conventional machining processes and those of single-and double-type gears manufactured using the cold extrusion process. Moreover, the material properties of the extruded helical gears are compared with the conventionally machined gears. In conclusion, the extruded gears exhibited a higher strength while consuming less energy during their manufacture than the gears manufactured using the conventional machining processes. Further, this alternative process is more cost effective as it generates less waste and exhibits high productivity compared to the conventional machining processes.
\end{abstract}

\section{Introduction}

Society is very concerned about the rapid depletion of natural resources and the changes in the environment owing to global warming. In particular, carbon emissions, energy consumption, and increased amounts of industrial waste resulting from the manufacturing of metal parts not only lead to environmental pollution, but also destroy ecosystems. In an attempt to solve this issue, sustainable production, which aims to minimize the environmental impact throughout the lifecycle of a product, has gained considerable attention, with research being conducted in this area. ${ }^{1-2}$ Fig. 1 illustrates sustainable production.

In general, sustainable production implements process optimization through process conversion. Helical pinion gears, which are used in the automatic transmissions of automobiles, are precision processed using hobbing and shaving processes, which unfortunately present problems such as lower rates of material recovery, higher energy consumption, and higher carbon emissions, relative to forging. ${ }^{3}$ These drawbacks may potentially result in lower productivity, increased costs, increased output of industrial waste, and contribute to climate change.
Alternatives to this conventional machining include forging, extruding, and rolling, all of which increase the material recovery rates and productivity. ${ }^{3}$

In this study, we examined the process of cold extrusion and analyzed its suitability for the environmentally friendly production of helical pinion gears (Fig. 2). In the present study, cold extrusion, which is a near net shape process, replaced the conventional machining process. A helical pinion gear requires high precision in the

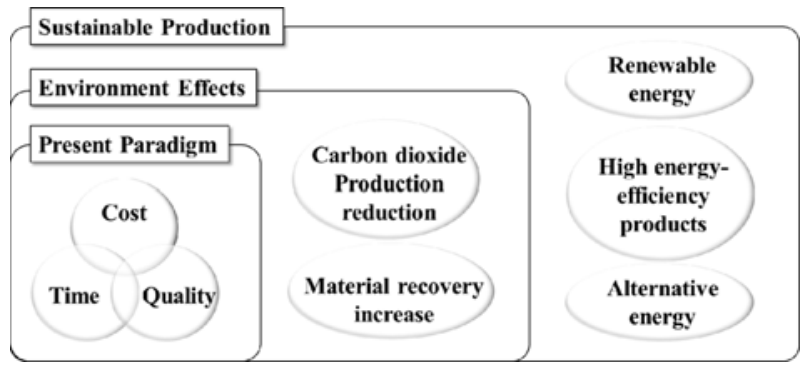

Fig. 1 Sustainable production 
manufacture of its tooth profile, and hence, its die design has to be based on a systemized analysis and the effective use of the initial billet. Concurrently, the consumption of less energy in the pre- and postprocesses should be considered in the die design process. ${ }^{4-6}$

To analyze the effect of changing this manufacturing process on the environment, we quantitatively analyzed the rates of material recovery. The present analysis of energy consumption and carbon emissions resulting from the manufacturing methods and types (Fig. 3) of helical pinion gears conformed to the Life Cycle Assessment (LCA) technique in accordance with ISO 14000. We also performed a quantitative analysis of the energy consumption and carbon emissions of each of the processes used to produce the initial billets. The effect on product quality was analyzed by testing the tooth accuracy of the extruded product. We also analyzed how the strength of the two gears was enhanced by examining their microstructures and flow-lines, and by subjecting them to a hardness test.

\section{Manufacturing using Cold Extrusion Process ${ }^{4}$}

The cold forging process can minimize the changes in shape that occur after product forming, thus increasing the precision of the final product. Moreover, less work is required in the post-processes because cold forging produces a workpiece that is close to the final shape of the product (a near net shape process). However, in comparison with hot forging, the die failure rates are rather high because of the higher load on the billet and punch, and therefore, careful die design is essential. The die design for the cold extrusion of helical pinion gears is closely related to the angle of entrance and the diameter of the initial billet.

The helical pinion gear that we considered in this study was previously studied by Jeong et al.. ${ }^{4}$ Their results are summarized here.

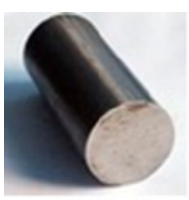

Initial

Billet

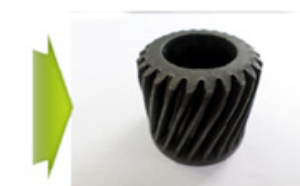

Cold Extrusion

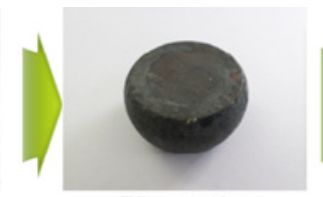

Upsetting

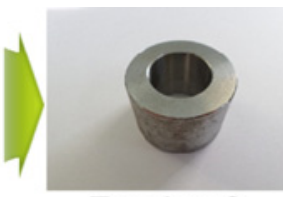

Forging \& Turning

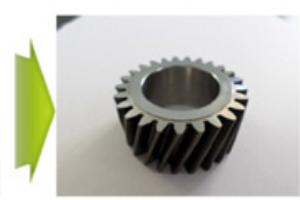

Turning

Fig. 2 Helical pinion gear manufactured using the cold extrusion process
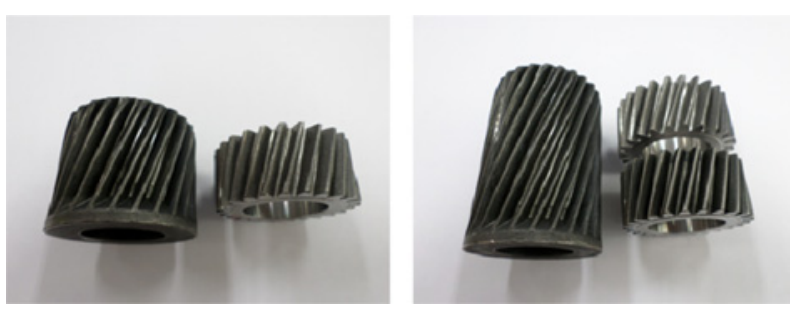

Fig. 3 Extruded helical gear: single-type (left), double-type (right)

They used Finite Element Analysis (FEA) to analyze the effects of the angle of entrance and the diameter of the initial billet during the forming of a helical pinion gear, and then optimized the form. The results of FE simulation showed that filling rarely failed when the angle of entrance was $45^{\circ}$. Hence, the punch load was low during cold extrusion (Fig. 4). An analysis of the fill rate of the gear was used to estimate the diameter of the initial billet. Fig. 4 shows the formability of the helical pinion gear for an area reduction rate of approximately $27 \%$. Reasonable fill rates were observed throughout the first half of the tooth profile. Given this degree of formability, the shape of the initial billet was determined as shown in Fig. 5. In addition, they analyzed the friction between the die and the punch. The suitability friction factor was defined as 0.1 .

Using finite element analysis, Jeong et al. expected that normal pressure would be applied to the left- and right-side tooth surfaces of the helical pinion gear. During the cold extrusion of a helical pinion gear, normal pressure was applied to the right side of a tooth. Then, during ejection, normal pressure was applied to the left side of a tooth. As a result, the accuracy of the helical pinion gear was improved.

\section{Environmental Effects}

During the manufacture of a metal product, the main causes of environmental pollution are the use of manufacturing equipment over time and the resulting metal waste. ${ }^{7}$ Therefore, to assess the environmental effects of switching from one manufacturing process to another, we analyzed the energy consumption and $\mathrm{CO}_{2}$ emissions of the manufacturing processes used to produce helical pinion gears. These

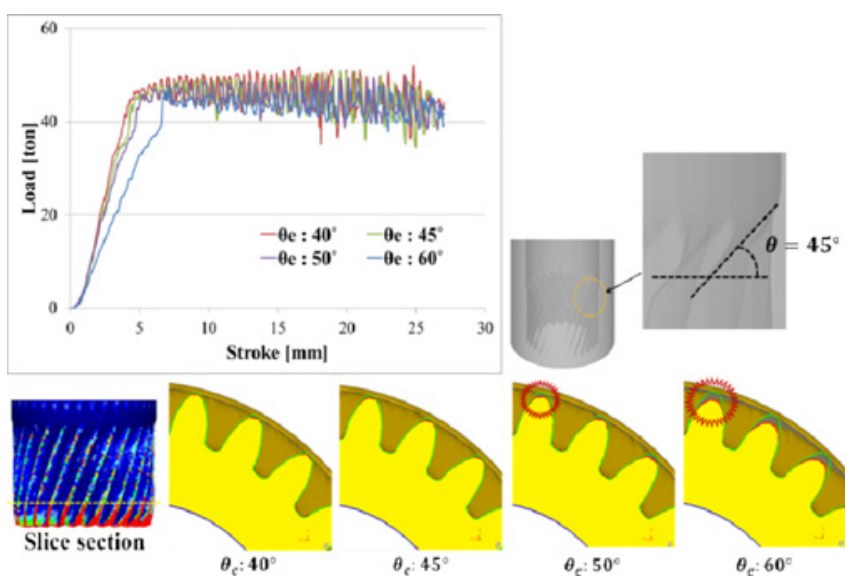

Fig. 4 Section of helical pinion gear ${ }^{4}$
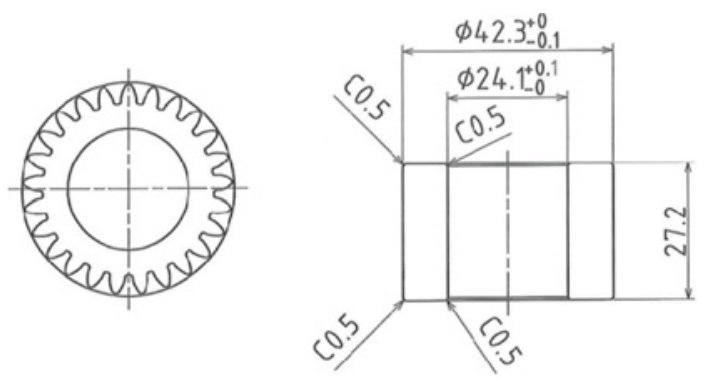

Fig. 5 Shape of initial billet 
processes include the production of the initial billet, forming and processing, and post-processing. The present analysis of the environmental effects of the gear manufacturing followed the LCA technique in accordance with ISO 14000. The carbon emissions can be expressed by equation (1):

$$
G_{j-\text { energy }(\text { production })}=\frac{\sum_{i}\left(M_{i j} \times E_{i}\right)}{P_{j}}
$$

where $G_{j}$ is the amount of carbon emissions produced as a result of using fuel during the manufacture of products, $\mathrm{M}_{\mathrm{ij}}$ is the annual amount of fuel and energy used to manufacture products, $\mathrm{E}_{\mathrm{i}}$ is the fuel emission factor, and $P_{j}$ is the annual production of products. In this study, $G_{j}, M_{i j}$, $E_{i}$, and $P_{j}$ were used as the data for LCA from a commercial program GRANTA (the energy cost for tooling was not considered).

Fig. 6 shows the amount of energy consumed for manufacturing helical pinion gears using the cold extrusion and conventional machining processes. The present analysis showed a reduction in the energy consumption of approximately $25 \%$ and $49 \%$ for the single- and double-type extrusion processes, respectively, in comparison with a gear manufactured using the machining processes.

Table 1 lists the energy consumption and $\mathrm{CO}_{2}$ emissions for the manufacture of billets for helical pinion gears. The manufacture of the billet for machining consumed 8.9 MJ, whereas that for the double-type helical pinion gear consumed $6 \mathrm{MJ}$. The $\mathrm{CO}_{2}$ emissions were reduced by $40 \%$, compared to those for the billet necessary for the conventional machining. These results arose as a result of the initial billet size being different.

In addition, the material recovery rates increased as a result of changing the process. Material recovery is calculated by comparing the volume of each billet. Fig. 7 shows the rates of material recovery after

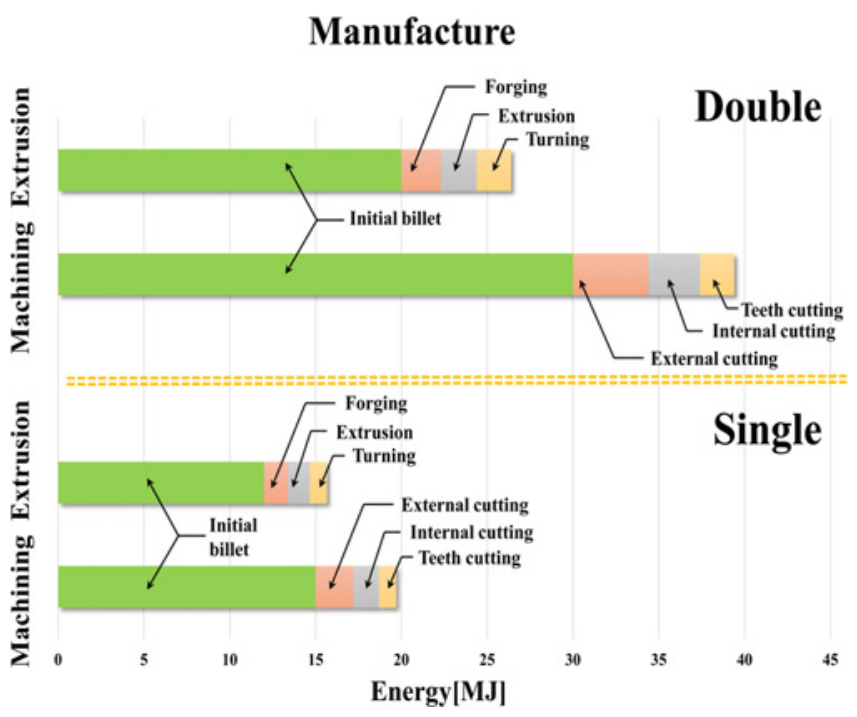

Fig. 6 Energy consumption for conventional machining and cold extrusion

Table 1 Energy and $\mathrm{CO}_{2}$ impact for the material

\begin{tabular}{ccc}
\hline & Energy $[\mathrm{MJ}]$ & $\mathrm{CO}_{2}[\mathrm{~kg}]$ \\
\hline Machining & 8.9 & 0.649 \\
\hline Extrusion: Single & 7.3 & 0.551 \\
\hline Extrusion: Double & 6 & 0.459 \\
\hline
\end{tabular}

cold extrusion. The material recovery rates for the single- and doubletype helical pinion gears increased by approximately $58 \%$ and $91.2 \%$, respectively, in comparison with the gears that were produced by machining. Therefore, cold extrusion is sustainable and eco-friendly. In addition, it is possible to use alternative processes to prevent environmental pollution, while saving energy and improving productivity.

\section{Assessment of Helical Pinion Gear}

\subsection{Flow-Line and Hardness Improvement}

A helical pinion gear manufactured using the conventional machining processes shows high precision in molding but its strength is compromised due to the flow-line cut-offs. The flow-line affects the durability of products and their fatigue strength. Therefore, a helical pinion gear manufactured using the conventional machining processes exhibits some drawbacks. However, a helical pinion gear manufactured using cold extrusion does not exhibit these flow-line cut-offs, as shown in Fig. 8, and showed compaction of the metal microstructure owing to plastic working, which potentially enhances the strength of the gear.

The strength of a helical pinion gear can be assessed from the strength of its center and its surface. We assessed these strengths by performing hardness tests on helical pinion gears that were manufactured using both the machining process and the alternative process. Fig. 9 shows the sections on which the hardness tests were

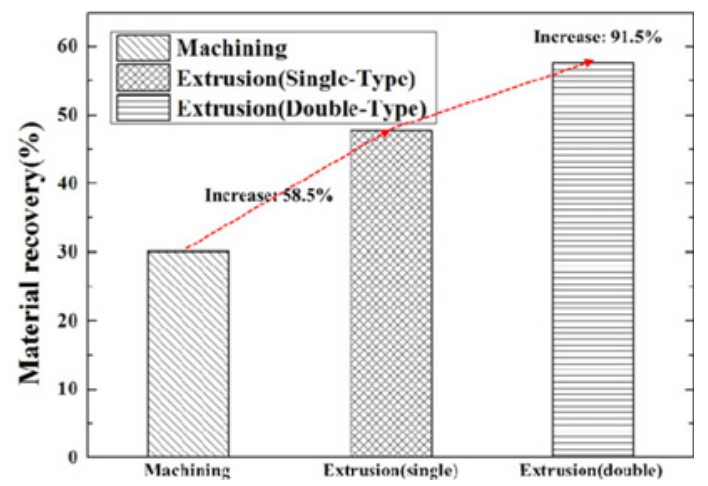

Fig. 7 Material recovery

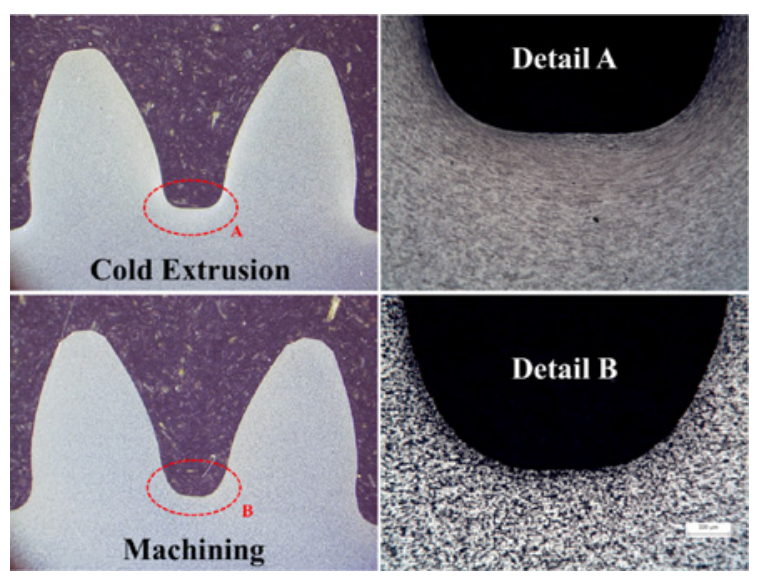

Fig. 8 Metal microstructure and flow-line 
performed. The hardness of the helical pinion gear was measured from its surface to its center, at intervals of $1 \mathrm{~mm}$. Fig. 10 shows the results of the Vickers hardness tests. Regardless of the measurement point, the gear manufactured using cold extrusion showed a higher hardness value than the gear manufactured using the conventional machining processes, with the value of the hardness being an average of $37 \%$ higher. These results show that the strength of the helical pinion gear manufactured using the cold extrusion process was enhanced, suggesting that the cold extrusion process contributes to increased hardness. In addition, these results confirm that the cold extrusion process produces a more sustainable product because extruded products have a higher durability than machined products.

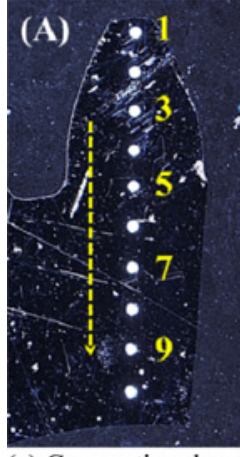

(a) Conventional machining

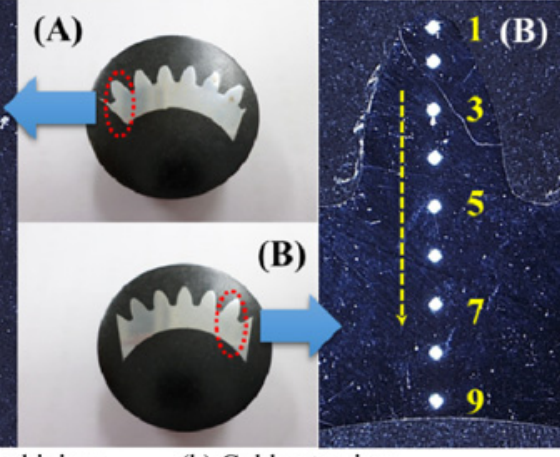

(b) Cold extrusion
Fig. 9 Sections used for the hardness tests

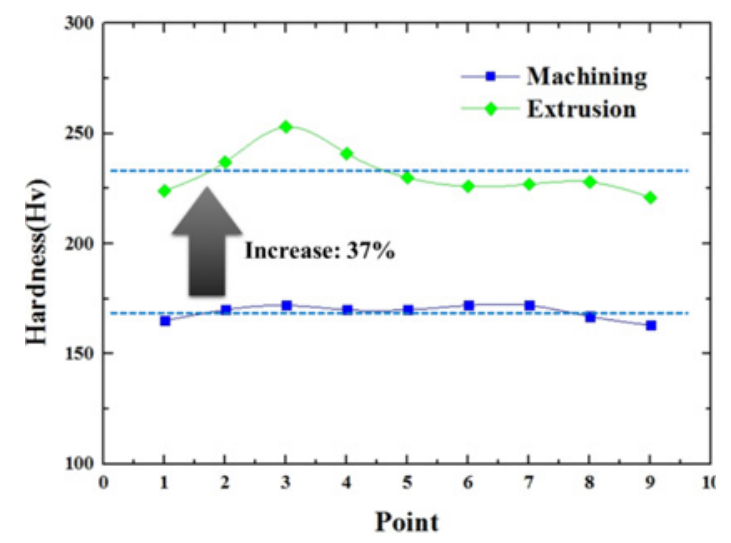

Fig. 10 Hardness test results

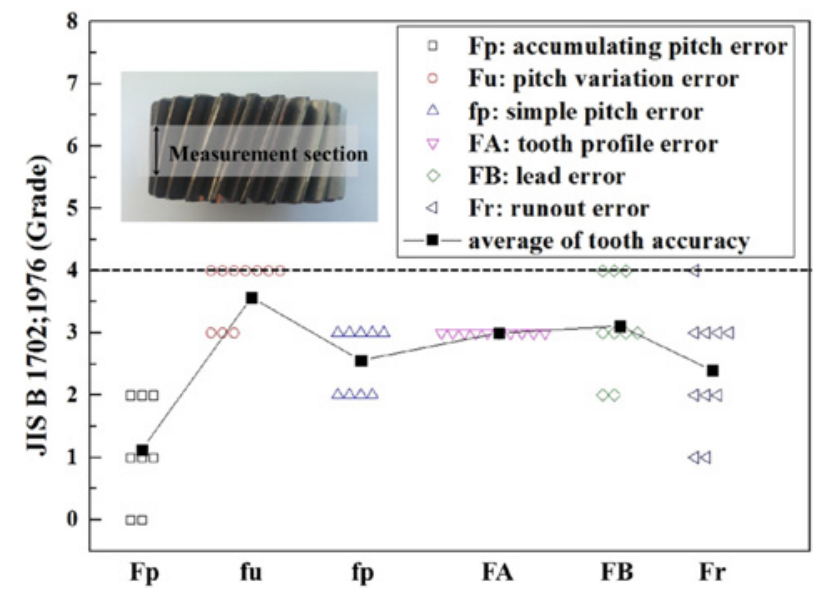

\subsection{Accuracy of Gear}

The tooth accuracy of a helical pinion gear affects vibration, noise, and defects. Therefore, the grade of a helical gear must be verified by measuring its accuracy. Fig. 11 shows the results of measuring the tooth accuracy of the cold extrusion gears. Measurements were performed on a total of ten gears. The tooth accuracy test was performed using a Leitz PPM-C 700. The minimum accuracy requirement for helical pinion gears used in automobile transmissions is grade 3. So in this study, the design standard for the extruded gears was set to grade 4 because the gear accuracy was increased by shaving process.

The grades of the helical pinion gear were assessed by referring to the JIS B $1702 ; 1976$ standard. The average grade of each gear is Fp: grade 2, fu: grade 3.5, fp: grade 2.5, FA: grade 3, FB: grade 3, and Fr: grade 2.5 . The helical pinion gears, manufactured using the proposed process, were confirmed as being classifiable as grade 4 . These results show that the alternative process cannot only produce teeth of the necessary accuracy but also improve the efficiency of the manufacturing.

\section{Conclusion}

In the present study, we used the LCA technique to analyze the environmental effects of changing the manufacturing process. The results showed that the cold extrusion process reduced the energy consumption in the manufacture of single- and double-type gears by $25 \%$ and $49 \%$, respectively, in comparison to conventional machining processes, and also reduced $\mathrm{CO}_{2}$ emissions. The rate of material recovery was increased by $91.2 \%$ relative to the conventional machining processes. Further, the hardness of the helical pinion gear, manufactured using cold extrusion, increased by approximately $37 \%$. In addition, the measured tooth accuracy for the helical pinion gear showed that it is an effective manufacturing method. These results show that changing the process can reduce energy consumption and $\mathrm{CO}_{2}$ emissions, as well as increase productivity, leading to an environmentally friendly and highly efficient manufacturing process. This means that the proposed process is greener than the conventional machining process for manufacturing helical pinion gears.

\section{REFERENCES}

1. Hunkeler, D. and Vanakari, E., "EcoDesign and LCA Survey of Current Uses of Environmental Attributes in Product and Process Development," Int. J. Life Cycle Assess., Vol. 5, No. 3, pp. 145-151, 2000.

2. Zhigang, J., Hua, Z., and John, W., "Development of an Environmental Performance Assessment Method for Manufacturing Process Plans,” Int. J. Adv. Manuf. Tech., Vol. 58, No. 5-8, pp. 783790, 2012.

3. Jeong, M., Lee, S., Sung, J., and Choi, T., "Green Alternative Processing Technology for a Spring Guide Pin of Stamping Die Set,” Int. J. Precis. Eng. Manuf., Vol. 13, No. 7, pp. 1239-1242, 2012.

Fig. 11 Tooth accuracy of helical pinion gears 
4. Jeong, M., Lee, S., Yoon, J., and Choi, T., "Green Manufacturing Process for Helical Pinion Gear Using Cold Extrusion Process,” Int. J. Precis. Eng. Manuf., Vol. 14, No. 6, pp. 1007-1011, 2013.

5. Zhang, Q., Kang, J., Li, Q., and Lyu, S., "The Calculation and Experiment for Measurements over Pins of the External Helical Gears with an Odd Number of Teeth,” Int. J. Precis. Eng. Manuf., Vol. 13, No. 12, pp. 2203-2206, 2012.

6. Jung, S., Kang, M., and Kim, C., "A Study on the Extrusion by a Two-Step Process for Manufacturing Helical Gear," Int. J. Adv. Manuf. Tech., Vol. 41, No. 7-8, pp. 684-693, 2009.

7. Frischknecht, R., "LCI Modelling Approaches Applied on Recycling of Materials in View of Environmental Sustainability, Risk Perception and Eco Efficiency,” Int. J. Life Cycle Assess., Vol. 15, No. 7, pp. 666-671, 2010.

8. Park, Y., Yoon, J., and Yang, D., "Finite Element Analysis of Steady-State Three-Dimensional Helical Extrusion of Twisted Sections using Recurrent Boundary Conditions,” Int. J. Mech. Sci., Vol. 36, pp. 137-148, 1994.

9. Park, Y. and Yang, D., "Finite Element Analysis for Precision Cold Forging of Helical Gear using Recurrent Boundary Conditions," Journal of Engineering Manufacture, Vol. 212, No. 3, pp. 231-240, 1998. 